\section{Reducing the European healthcare budget with generics and biosimilars}

The world market for medicinal products is expected to reach US\$1 trillion in 2014. Global spending on medicines is expected to grow to nearly US\$1.2 trillion by 2017 [1]. As governments around the world try to rein in healthcare expenses, generics and biosimilars can play a major role in reducing this budgetary burden.

\section{Intellectual property}

Intellectual property (IP) rights are of critical value in a knowledgebased society and pharmaceutical companies are particularly dependent on appropriate patent protection and enforcement. Equally, effective competition between originator and generic drugs generates incentives for originator pharmaceutical companies to continue investing in research and development.

\section{Budget constraints}

Due to a combined effect of the so-called 'patent cliff' (when a large number of key small molecule brand-name drugs become open to competition from generics) and the current economic crisis, in recent years most OECD (Organisation for Economic Co-operation and Development) countries have even experienced a consolidation or decrease in pharmaceutical expenditure as a share of total healthcare expenditure. Most of these savings have been achieved by the replacement of expensive brand-name drugs with low cost generics.

Other changes have also been introduced to reduce spending on medicines. Changes affecting reimbursement lists and procedures, e.g. de-listings, introduction of positive and/or negative lists; and the reference price system, i.e. changes in pricing methodology allowing lower reference prices, broader clusters of similar medicines, and/or the pricing of generics in a cluster ('generic price link') are being made.

Measures to increase the uptake of generics, such as making prescribing by international non-proprietary name mandatory and the use of public awareness-raising campaigns, have been frequently used.

Despite these measures, pharmaceutical expenditure still accounts for a considerable percentage of total healthcare spending in Europe. In 2011, spending on drugs as a percentage of total healthcare spending ranged from $6.8 \%$ in Denmark to $33.4 \%$ in Hungary; followed by Greece (28.5\%) and the Slovak Republic (27.4\%).

\section{European Union measures}

The European Union (EU) has introduced several measures, such as a centralized procedure for the authorization of medicines, rules facilitating the approval of generics, support to small- and medium-sized enterprises (SMEs), and regulatory data protection incentives to promote innovation while assuring timely access of patients to medicines.

\section{Biosimilars}

Biosimilars can also play a major role in improving public health since they address the need for the responsible allocation of public funds while opening up promising treatment options for patients by increasing their affordability. However, to realize the potential benefits that biosimilars offer requires not only a robust regulatory framework such as the one in place in the EU, but also effective risk management.

Experience to date suggests that the most important conditions required for market uptake of biosimilars are factors such as:
i. physician perception
ii. patient acceptance
iii. local pricing and reimbursement regulations
iv. procurement policies and terms.

Fostering the informed uptake and improving early access to high quality biosimilars on the basis of the EU's regulatory framework, i.e. through access to unbiased information and education of patients, healthcare professionals and payers, while closely monitoring the EU's market penetration of biosimilars may contribute to the success of the dual objectives of improving overall public health and the sustainability of Member States' healthcare systems. 
According to IMS Health, although biosimilars are a small segment in the total pharmaceutical market $(\sim 1 \%)$, they have experienced exceptional growth (38\% in 2012). Biosimilars' share of the accessible European market has grown steadily from their launch and is now at 18\%. Biosimilars have a 13\% share of the growth hormone market, $19 \%$ of the erythropoietin market, and $49 \%$ of the granulocyte colony-stimulating factor market [2].

The per capita uptake of biosimilars and the size of the accessible market however differ between European markets [3]. For example, in the UK biosimilars make up only $30 \%$ of the volume market share of their reference products, despite the fact that the UK has one of the highest market shares of generics in Europe. In 2010, $83 \%$ of prescriptions in England were prescribed and $67 \%$ were dispensed as generics [4]. The UK biosimilars uptake is significantly lower than in Germany, where biosimilars have around 50\% volume uptake [5].

\section{Continued effort}

Member States' governments will need to continue their efforts to limit the future growth in medical expenditures, especially for medicines. The use of generics and biosimilars is therefore expected to be promoted as a lower-cost alternative by public and private payers. However, lack of competition and insufficient or ineffective policies promoting the use of generics and biosimilars can limit the ability of governments to implement budgetary savings.

\section{Competing interests: None.}

Provenance and governance: Article abstracted based on published scientific or research papers recommended by members of the Editorial Board, internally peer reviewed.

Michelle Derbyshire, PhD, GaBI Online Editor

\section{References}

1. European Commission. Commission staff working document. Pharmaceutical industry: a strategic sector for the European economy. 1 August 2014. SWD(2014) 216 final/2 [homepage on the Internet]. 2014 Aug 1 [cited 2014 Oct 16]. Available from: http://ec.europa.eu/enterprise/sectors/healthcare/files/docs/pharmastrategy_en.pdf

2. Dunn C. Biosimilar accessible market: size and biosimilar penetration. Prepared for EFPIA-EGA-EuropaBio, April 2012

3. GaBI Online - Generics and Biosimilars Initiative. Use of biosimilars in Europe [www.gabionline.net]. Mol, Belgium: Pro Pharma Communications International; [cited 2014 Oct 16]. Available from: www.gabionline.net/Reports/Use-ofbiosimilars-in-Europe

4. Health and Social Care Information Centre. Prescriptions Dispensed in the Community Statistics for England - 2000-2010 [NS]. 27 July 2011 [homepage on the Internet]. 2014 Oct 16 [cited 2014 Oct 16]. Available from: http://www.hscic. gov.uk/pubs/presdisp2000-10

5. GaBI Online - Generics and Biosimilars Initiative. UK biosimilars uptake lower than in some other EU countries [www.gabionline.net]. Mol, Belgium: Pro Pharma Communications International; [cited 2014 Oct 16]. Available from: www.gabionline. net/Reports/UK-biosimilars-uptake-lower-than-in-some-other-EU-countries DOI: 10.5639/gabij.2014.0304.046

Copyright (C) 2014 Pro Pharma Communications International 